\title{
Developing Navigation Competencies to Care for Older Rural Adults with Advanced Illness*
}

\author{
Wendy Duggleby, ${ }^{1}$ Carole A. Robinson, ${ }^{2}$ Sharon Kaasalainen, ${ }^{3}$ Barbara Pesut, ${ }^{4}$ \\ Cheryl Nekolaichuk, ${ }^{5}$ Roderick MacLeod, 6 Norah C. Keating, ${ }^{7}$ Anna Santos Salas, ${ }^{8}$ \\ Lars K. Hallstrom, ${ }^{9}$ Kimberly D. Fraser, ${ }^{10}$ Allison Williams, ${ }^{11}$ Kelly Struthers-Montford, ${ }^{12}$ and \\ Jennifer Swindle ${ }^{13}$
}

\begin{abstract}
RÉSUMÉ
Les navigateurs aident les adultes ruraux âgés avec des maladies avancées, ainsi que leurs familles, de se connecter aux ressources, à l'information, et aux gens qui peuvent améliorer leur qualité de vie. Cet article décrit le processus utilisé pour engager des experts-en vieillissement en milieu rural, les soins palliatifs en milieu rural, et la navigation-ainsi que les intervenants dans les collectivités rurales, d'élaborer une définition conceptuelle d'une telle navigation et de délimiter les compétences pertinentes pour la prise en charge de cette population. Un document de discussion sur les considérations importantes pour la navigation dans cette population a été développé, suivi d'un processus Delphi en quatre étapes avec 30 membres invités experts. Les résultats de l'étude ont abouti à cinq compétences générales de navigation pour les fournisseurs de soins de santé qui prennent soin des personnes âgées rurales et de leurs familles à la fin de vie: la capacité de fournir le dépistage des patients / famille; à préconiser pour le patient / famille; de faciliter les relations avec la communauté; de coordonner l'accès aux services et aux ressources; et de promouvoir l'engagement actif. Les compétences particulières ont également été développées. Ces compétences constituent la base pour la recherche et le développement de programmes d'études en navigation.
\end{abstract}

\begin{abstract}
Navigators help rural older adults with advanced illness and their families connect to needed resources, information, and people to improve their quality of life. This article describes the process used to engage experts - in rural aging, rural palliative care, and navigation - as well as rural community stakeholders to develop a conceptual definition of navigation and delineate navigation competencies for the care of this population. A discussion paper on the important considerations for navigation in this population was developed followed by a four-phased Delphi process with 30 expert panel members. Study results culminated in five general navigation competencies for health care providers caring for older rural persons and their families at end of life: provide patient/family screening; advocate for the patient/family; facilitate community connections; coordinate access to services and resources; and promote active engagement. Specific competencies were also developed. These competencies provide the foundation for research and curriculum development in navigation.
\end{abstract}

1 Faculty of Nursing, University of Alberta

2 University of British Columbia, Okanagan Campus, School of Nursing

3 School of Nursing, McMaster University

4 University of British Columbia, Okanagan Campus, School of Nursing

5 Division of Palliative Care Medicine, Department of Oncology, University of Alberta

6 HammondCare and University of Sydney, Greenwich Hospital, Australia

7 International Association of Gerontology and Geriatrics, Department of Human Ecology, Department of Family Medicine, University of Alberta

8 Faculty of Nursing, University of Alberta

9 Alberta Centre for Sustainable Rural Communities; Political Studies (Augustana Faculty) and REES (ALES), University of Alberta

10 Faculty of Nursing, University of Alberta

11 School of Geography and Earth Sciences, McMaster University

12 Department of Sociology, University of Alberta

13 Faculty of Nursing, University of Alberta

* Funding for this initiative was provided by a Canadian Institutes of Health Research Planning and Dissemination Grant. We would also like to acknowledge the co-investigators (Dan Cooper, Donna Goodridge, Kyle Whitfield, Robin Fainsinger, Sharon Watanabe, Terri Woytkiw), the facilitators (Dale Reesor and Jim Boyes) for the Phase Four Delphi event, and the many research assistants who supported this project. 
Manuscript received: / manuscrit reçu : 16/09/14

Manuscript accepted: / manuscrit accepté : 24/07/15

Mots clés : vieillissment, navigation, soins palliatifs, rural -e -aux, adultes âgés (aînés), compétences

Keywords: aging, navigation, palliative care, rural, older adults, competencies

La correspondance et les demandes de tirés-à-part doivent être adressées à : / Correspondence and requests for offprints should be sent to:

Wendy Duggleby, Ph.D., R.N., AOCN

Professor and Nursing Research Chair, Aging and Quality of Life

Faculty of Nursing

University of Alberta

3rd Level ECHA

11405 - 87th Ave.

Edmonton, AB T6G 1C9

(wendy.duggleby@ualberta.ca)

Patient navigation is an emerging phenomenon of interest in health care as an approach to provide effective care coordination and enhanced patient satisfaction (Calhoun et al., 2010). A major recommendation from the Parliamentary Committee on Palliative and Compassionate Care is that navigators are needed to guide individuals with advanced illness and their families through the complexities of the health care system (Parliamentary Committee on Palliative and Compassionate Care, 2011). In particular, there is a critical need to have skilled navigators in rural settings. For rural older persons, the realities of dying and death include isolation, lack of services, the necessity of commuting for care, and high levels of caregiver burden (Castleden, Crooks, Schuurman, \& Hanlon, 2010; Crooks \& Schuurman, 2008; Duggleby et al., 2010, 2011; Goodridge \& Duggleby, 2010; Lockie, Bottorff, Robinson, \& Pesut, 2010; McKee, Kelley, GuirguisYounger, MacLean, \& Nadin, 2010; Robinson, Pesut, \& Bottorff, 2010; Robinson et al., 2009; Wilson, Truman, et al., 2009). Palliative care services are lacking in rural Canada and, along with a lack of other health care services, have caused inequities in access to services in rural communities that are not experienced in urban areas (Robinson et al., 2010).

Although several models of navigation exist in the literature (Case, 2011; Fillion et al., 2012; Pedersen \& Hack, 2011), they were developed for cancer care, not palliative care, and they do not appear to reflect the unique issues of rural older adults with advanced illness. Rural and urban comparisons are difficult because of the diversity of rural contexts (Keating, 2008). However, in studying rural contexts there appear to be some commonalities that suggest there are unique issues for a person with advanced illness. For example, McKee et al. (2010) suggested that in rural contexts, when a person is dying, the entire community is affected, and care for the dying person is an expression of reciprocity that characterizes rural community life.
Thus, the conceptualization and subsequent development of navigation competencies specific to the care of older persons living in rural areas with advanced illness is an important step to improve older persons' quality of life.

In this article, we describe a four-phased Delphi process conducted with experts in rural aging, rural palliative care, and navigation, as well as with community stakeholders, to develop navigation competencies specifically oriented to the care of older persons with advanced illness and their families living in rural areas.

\section{Background}

The focus of the navigation competencies literature has been on cancer care. In cancer care, the goal of patient navigation is to address cancer health disparities by eliminating barriers to diagnosis, treatment, and services for vulnerable populations who have limited or difficult access to health care resources (Calhoun et al., 2010). The term navigator has been applied to any type of service that assists individuals in overcoming obstacles from screening to treatment, and in coping with challenges during survivorship (Wells et al., 2008). One of the major challenges in the literature is the lack of a generally accepted definition for patient navigation and very little consensus on the actual roles and responsibilities of navigators (Wilcox \& Bruce, 2010). The literature also uses the terms patient navigation program and patient navigator interchangeably. In the Canadian health care system, navigators have been called case managers, clinical coordinators, cancer support nurses, follow-up nurses, breast specialists, breast cancer coordinators, and patient navigators (Fillion et al., 2012).

The Canadian Partnerships Against Cancer (CPAC) (2012) and the National Case Management Network (NCMN) (2012) have developed definitions of navigation and related competencies. CPAC (2012) has defined 
navigation as "a system of services and resources that are mobilized based on the immediacy and severity of patients' needs. It is a proactive, intentional process of collaborating with a person and his or her family to provide guidance as they negotiate cancer care" (p. 6). The focus of the CPAC navigation definition and resulting competencies have been on patient needs and cancer care. Accordingly, this definition and resulting competencies may not be applicable to rural palliative care for multiple reasons. For example, palliative care utilizes a family-centred approach (Canadian Hospice Palliative Care Association, 2013a), so care is provided to both the family and patient. Although the CPAC definition does include the family, the competencies clearly have a patient focus for cancer treatment. Navigation competencies are needed that also include screening and access to services to support for family members.

The CPAC navigation definition and competencies have a focus on cancer care. Palliative care services include many chronic conditions, not only cancer, and traditionally exceed conventional definitions of health care to include social, psychological, and spiritual care (Canadian Hospice Palliative Care Association, 2013b). Additionally, cancer care emphasizes treatment whereas the palliative approach emphasizes quality of life as a goal (World Health Organization, 2013). Consequently, navigation competencies in cancer care will have a significantly different focus than those needed in rural palliative care.

Rural Canada has very few health care services in general (Robinson et al., 2009), so navigation specific to this population should include accessing other community resources (in addition to health), and informal services. The NCMN (2012) has viewed navigation as helping clients to navigate the health and social care system by working with their networks to identify and address barriers. The NCMN identifies two key case management navigation competencies: (a) anticipate, identify, and help remove barriers to holistic care; and (b) facilitate safe and effective connections to services across settings. This definition recognizes the importance of the social care system and networks in addressing barriers to care, which is more reflective of rural aging. However, it does not address important concepts in rural aging described by Keating, Swindle, and Fletcher (2011) such as aging well, and the contributions that older adults make to their family, friends, and community. A definition and competencies of navigation for the care of older adults residing in rural areas are needed that reflect important rural aging concepts and perspectives. The purpose of this project was to develop health care provider competencies specific to the care of older persons with advanced illness living in rural areas.

\section{Method}

There were two main stages in the development of the navigation competencies: a discussion paper and a four-phased Delphi process. The first stage involved writing a discussion paper on rural aging and rural palliative care based on a literature review (described in more detail later). This paper identified important considerations in the development of the competencies. From this discussion paper, the research team developed a conceptual definition of navigation and identified its purpose and goals.

\section{Delphi Process}

The second stage was a four-phased Delphi process suggested by Linstone and Turoff (2002) to develop the competencies.

\section{Participants}

The research team identified potential members of an international expert panel of researchers, knowledge users, and community stakeholders based on the inclusion criteria. The inclusion criteria for the expert panel were persons who had experience or expertise in rural palliative care, rural aging, or navigation. Team members sent the names and contact information of potential panel members to the Principal Investigator (PI). The PI then contacted potential panel members via email to determine if they were willing to participate in the process. They were provided with information about the purpose of the project and the Delphi process procedures. A return email agreeing to participate served as consent for the study. Thirty researchers, health care professionals, and community stakeholders were approached, and all agreed to participate.

\section{Data Collection}

In the first phase of the Delphi process, panel members were sent an email with a copy of the discussion paper and were asked to identify possible competencies for each of the navigation dimensions identified in the discussion paper. Their answers were then collated by the PI and her research coordinator and categorized into general areas of competencies (GACs). In the second phase, panel members were contacted via email and asked to rank all the specific competencies in each GAC in order of importance. The top five ranking competencies were then retained. In the third phase, panel members were asked via email to evaluate the competencies for importance of inclusion using a consensus tool. Competencies had to receive a 75 per cent consensus from expert panel members to be retained. A competency was removed if it ranked lower than the 75 per cent threshold. 
The fourth phase of the Delphi process was a face-toface meeting with 24 of the expert panel's members involved in the first three phases of the Delphi process, including decision makers, knowledge users, researchers, and rural community members. Six panel members were unable to attend. The goal of the fourth phase was to achieve consensus around a preliminary set of navigation competencies for the care of older rural adults with advanced illness and their families. Two facilitators who were experts in a process of developing competencies guided the process. They utilized a process entitled "Developing a Curriculum (DACUM)" (Norton, 1997) whereby expert practitioners are assembled to consider a job, vocation, role, or courses of studies in their field. In this case, the DACUM process was used to describe the navigation skills necessary for the care of older rural adults with advanced illness and their families.

\section{Results}

\section{Stage 1: Discussion Paper}

In order to define navigation and identify challenges and issues to consider for the care of older rural adults, we completed a discussion paper on aging, rural palliative care and navigation. The full discussion paper can be viewed at www.nurs.ualberta.ca/livingwithhope. Considerations for navigation competencies identified in the discussion paper included the following: (a) finding the "best fit" for the older person and their environment (Keating, 2008; Keating, Eales, \& Phillips, 2013; Keating, Swindle, \& Fletcher, 2011); (b) filling the need to foster independence (Duggleby et al., 2011; Pesut, McLeod, Hole, \& Dalhuisen, 2012; Wilson, Fillion, Thomas, Justice, Bhardwaj, et al., 2009); (c) fostering community connections (Crooks \& Schuurman, 2008; Duggleby et al., 2011; McKee et al., 2010; Robinson et al., 2010; Wilson, Fillion, Thomas, Justice, Veillette, et al., 2009); (d) accessing both formal and informal services (Kelley, 2007; Robinson et al, 2009); (e) applying a family-centric approach (Canadian Hospice Palliative Care Association, 2012; Duggleby et al., 2010, 2011; Robinson, Pesut, \& Bottorff, 2012); and (f) focusing on the palliative approach with quality of life as a goal (Canadian Hospice Palliative Care Association, 2013b).

"Best fit" is a concept that reflects the diversity of rural communities, older persons, and their interactions with the environment (Keating et al., 2013). Although people are continuously interacting with the physical and social contexts in which they live, they are not passive recipients (Keating, 2008). Instead, older adults, through their responses to their contexts, and at times through purposeful interactions, change the contexts in which they live. For example, an older adult may decide to participate in a social activity and as a result expand their network. Thus, older adults interact with their environment in ways that are critical to their health and well-being (Keating, 2008). With the diversity of older adults and their communities, it is important to consider both the best fit between the needs of the older adults in a given community and the community resources available to them (Keating et al., 2013).

Rural persons' connection to their communities and their need for independence were found to be equally and highly valued by rural populations (Duggleby et al., 2011). For example, in an ethnographic study, Wilson et al. (2009a) found that a good rural death was defined against the backdrop of rural community values in terms of independence and community connections. Accordingly, fostering community connections and helping older persons maintain independence as much as possible were viewed as important aspects of navigation.

Another consideration for the navigation competencies was the use of a family-centred and palliative approach. The palliative approach views patient/family (familycentred approach) as the unit of care with the goal of optimizing quality of life for both the patient and family. As well, it reflects a shift from specialist-led models to a generalist multidisciplinary approach (Canadian Hospice Palliative Care Association, 2013b). There is a debate in the literature, particularly among rural physicians, about whether palliative care should be delivered through a specialist or a generalist model in rural settings (Robinson et al., 2010). The lack of physicians in many rural areas in Canada also means there are few palliative care specialists (Kaasalainen et al., 2012). There is also a debate in the literature as to whether the primary responsibility for palliative care should rest on formal specialists, or it should be a fundamental part of all primary care. The Canadian Hospice Palliative Care Association (2013b) suggests that a palliative approach that integrates the palliative ideals into primary care will increase the access to some palliative care services in Canada.

In working together to write the discussion paper, our research team developed the definition of rural navigation as a framework to guide the development of the competencies. Rural navigation is working in collaboration with patients, families, and communities (a) to negotiate the best fit between the needs of older rural persons, their families and communities, and available resources; (b) to improve access to needed informal and formal services and resources at the end of life (including death) and bereavement; (c) to promote quality of life; (d) to support independence; and (e) to facilitate community connections utilizing a family-centric, culturally safe, palliative approach.

The principles underpinning this conceptual definition were then translated into proposed goals of navigation which included (a) promoting an optimal quality of life 
(physical, emotional, psychological, relational, financial, existential, and spiritual), (b) fostering independence, and (c) facilitating community connections. These goals are also congruent with the rural aging literature that identified an important rural lens through which to view rural navigation: quality of life, independence, and social connections (Keating et al., 2011).

\section{Stage 2: Delphi Results}

In the first phase of the Delphi process, the participants brainstormed 66 competencies which were then grouped into five general area competencies (GACs). These GACs were as follows: (a) provide patient/family screening, (b) advocate for patient/family, (c) facilitate community connections, (d) coordinate access to services and resources, and (e) promote active engagement. Associated with each GAC were more-specific competencies. Panel members were asked to rank all the specific competencies in each GAC in order of importance (phase two). The top ranked 5 in each GAC were then sent to the expert panel members for phase three (25 competencies).

In phase three, we evaluated the competencies for importance of inclusion. Only one competency was removed during this process, as it ranked below the 75 per cent inclusion criterion resulting in 24 specific competencies. The competency that was removed was "encourage development of family/friend/community resource-based plans with minimal dependence upon professional support". It was not considered to be important to be included as there was another similar competency. In phase four at the face-to-face consensus meeting, both the general area and the specific competencies were reviewed once more with the addition of 12 more specific competencies. Consensus of the competencies that are important for rural navigation of older persons was achieved. These competencies are called "Navigation Competencies for Rural Older Adults (NCROA)" (Table 1) which included a contextual statement and definitions as well as five GACs and 36 specific navigation competencies. The contextual statement was as follows: The competencies reflect a family-centric approach, in that they are focused on the patient and family. Provision of navigation services commences when an older adult is deemed palliative (see definition below) and extends through bereavement.

\section{Definitions}

(1) Patient refers to older adults with advanced illness whether they are at home, in a long-term care or an acute care facility.

(2) Quality of life domains include these: physical, emotional, psychological, relational, financial, existential, and spiritual.
(3) Services for older adults may include these: psychosocial, emotional, spiritual, and physical supports to enable desired level of independence.

(4) Generalist health care providers are professionals who have training and provide palliative care, but are not considered specialists in palliative care.

(5) Family is defined broadly as relatives, friends, and neighbors.

(6) Palliative is defined as a person whose health care provider would not be surprised if they were to die in the next 6-12 months.

Table 1 presents the NCROA consisting of five GACs (A-E) which are not listed in order of importance or sequence. These GACs (a) provide patient/family screening, (b) advocate for the patient/family, (c) facilitate community connections, (d) coordinate access to services and resources, and (e) promote active engagement. Within each GAC are five to nine specific competencies that further delineate and describe the GACs. Figure 1 is a visual representation of the five GACs and their integration into the conceptual definition of navigation for older rural adults with advanced illness and their family. Quality-of-life priorities guide the navigation competencies which, within a context of best fit and the palliative approach, results in connecting older adults and their families with resources. The goal of navigation is optimal quality of life, independence, and community connections.

\section{Discussion}

The NCROA conceptual definition and competencies, developed through the two stages of a discussion paper and a four-phased Delphi process, reflects the values of independence, quality of life, and community connections, along with a family-centric and palliative approach. As a result, it differed significantly from the definitions and competences developed by the Canadian Partnerships Against Cancer (CPAC; 2012) and the National Case Management Network (NCMN; 2011). For example, the importance of independence resulted in a GAC entitled "promoting active engagement" and a specific competency under the "advocate for the patient/family" category of facilitating strategies for self-navigation. Facilitating selfnavigation is similar to the NCMN competencies that include coaching clients and social networks to self-navigate the health and social systems. The CPAC competencies focus on self-management of the disease and not self-navigation of the health care and social systems. In contrast, the NCROA guidelines include promoting active engagement of the patient and family by building their capacity to meet (a) their desired levels of independence and engagement in achieving their quality-of-life goals, and (b) promoting engagement in decision-making. 
Table 1: Navigation Competencies for Rural Older Adults (NCROA)

\begin{tabular}{|c|c|c|c|c|c|c|c|c|}
\hline $\begin{array}{l}\text { A. Provide } \\
\text { Patient/ } \\
\text { Family } \\
\text { Screening }\end{array}$ & $\begin{array}{l}\text { A1. Identify } \\
\text { patient diagnosis, } \\
\text { prognosis } \\
\text { and current } \\
\text { state of illness } \\
\text { progression, } \\
\text { and quality of } \\
\text { life transitions }\end{array}$ & $\begin{array}{l}\text { A2. Assess } \\
\text { patient/family } \\
\text { knowledge } \\
\text { of disease } \\
\text { progression and } \\
\text { quality-of-life } \\
\text { (QOL) concerns }\end{array}$ & $\begin{array}{l}\text { A3. Identify } \\
\text { patient/family } \\
\text { values and } \\
\text { beliefs regarding } \\
\text { end-of-life issues }\end{array}$ & $\begin{array}{l}\text { A4. Explain } \\
\text { and provide } \\
\text { information on } \\
\text { patient diagnosis, } \\
\text { prognosis and } \\
\text { current state of } \\
\text { disease progression, } \\
\text { and quality-of-life } \\
\text { transitions }\end{array}$ & $\begin{array}{l}\text { A5. Prioritize } \\
\text { patient/family } \\
\text { concerns } \\
\text { across QOL } \\
\text { domains }\end{array}$ & $\begin{array}{l}\text { A6. Evaluate } \\
\text { patient/family } \\
\text { capacity to } \\
\text { meet needs in } \\
\text { QOL domains } \\
\text { and illness } \\
\text { management }\end{array}$ & $\begin{array}{l}\text { A7. Determine } \\
\text { patient/family } \\
\text { preferred } \\
\text { engagement in } \\
\text { decision-making } \\
\text { and self-navigation }\end{array}$ & $\begin{array}{l}\text { A8. Identify } \\
\text { patient/family } \\
\text { knowledge } \\
\text { and perception } \\
\text { of available } \\
\text { options, and } \\
\text { community } \\
\text { resources }\end{array}$ \\
\hline $\begin{array}{l}\text { B. Advocate } \\
\text { for the } \\
\text { Patient/ } \\
\text { Family }\end{array}$ & $\begin{array}{l}\text { B1. Identify patient/ } \\
\text { family needs }\end{array}$ & $\begin{array}{l}\text { B2. Assist family } \\
\text { caregivers in } \\
\text { care provision } \\
\text { decisions }\end{array}$ & $\begin{array}{l}\text { B3. Identify barriers } \\
\text { to needed } \\
\text { resources }\end{array}$ & $\begin{array}{l}\text { B4. Advocate } \\
\text { to meet patient/ } \\
\text { family needs }\end{array}$ & $\begin{array}{l}\text { B5. Assist } \\
\text { patient/family } \\
\text { to overcome } \\
\text { service access } \\
\text { barriers }\end{array}$ & $\begin{array}{l}\text { B6. Advise } \\
\text { patient/family } \\
\text { on negotiating } \\
\text { for care and } \\
\text { services }\end{array}$ & $\begin{array}{l}\text { B7. Facilitate } \\
\text { strategies for } \\
\text { self-navigation }\end{array}$ & $\begin{array}{l}\text { B8. Facilitate } \\
\text { conflict } \\
\text { resolution }\end{array}$ \\
\hline $\begin{array}{l}\text { C. Facilitate } \\
\text { Community } \\
\text { Connections }\end{array}$ & $\begin{array}{l}\text { C1. Perform } \\
\text { environmental } \\
\text { scan for } \\
\text { community } \\
\text { services, care } \\
\text { providers, and } \\
\text { events }\end{array}$ & $\begin{array}{l}\text { C2. Identify } \\
\text { community } \\
\text { assets for } \\
\text { patient/family }\end{array}$ & $\begin{array}{l}\text { C3. Identify best-fit } \\
\text { for patient/ } \\
\text { family with } \\
\text { community } \\
\text { resources }\end{array}$ & $\begin{array}{l}\text { C4. Create } \\
\text { linkages to } \\
\text { local leaders, } \\
\text { professionals, } \\
\text { and resources }\end{array}$ & $\begin{array}{l}\text { C5. Broker } \\
\text { linkages } \\
\text { among local } \\
\text { knowledge } \\
\text { keepers and } \\
\text { resource } \\
\text { providers }\end{array}$ & $\begin{array}{l}\text { C6. Assist } \\
\text { patient/family } \\
\text { to build and } \\
\text { connect with } \\
\text { networks/ } \\
\text { connections }\end{array}$ & & \\
\hline \multirow[t]{2}{*}{$\begin{array}{l}\text { D. Coordinate } \\
\text { Access to } \\
\text { Services and } \\
\text { Resources }\end{array}$} & $\begin{array}{l}\text { D1. Identify } \\
\text { patient/family } \\
\text { concerns/needs }\end{array}$ & $\begin{array}{l}\text { D2. Develop } \\
\text { care plans } \\
\text { reflective of } \\
\text { patient/family } \\
\text { needs and } \\
\text { concerns }\end{array}$ & $\begin{array}{l}\text { D3. Assess patient/ } \\
\text { family need for } \\
\text { supports for } \\
\text { values-based } \\
\text { end-of-life care }\end{array}$ & $\begin{array}{l}\text { D4. Provide } \\
\text { family with } \\
\text { caregiving } \\
\text { and support } \\
\text { resources }\end{array}$ & $\begin{array}{l}\text { D5. Coordinate } \\
\text { access to } \\
\text { needed } \\
\text { services }\end{array}$ & $\begin{array}{l}\text { D6. Assess } \\
\text { patient/family } \\
\text { service usage }\end{array}$ & $\begin{array}{l}\text { D7. Facilitate } \\
\text { discussion } \\
\text { with patient/ } \\
\text { family regarding } \\
\text { advance care } \\
\text { planning and } \\
\text { goals of care }\end{array}$ & \\
\hline & $\begin{array}{l}\text { D8. Facilitate } \\
\text { patient/family } \\
\text { access to services } \\
\text { providing legal } \\
\text { wills and funeral } \\
\text { planning }\end{array}$ & $\begin{array}{l}\text { D9. Assist } \\
\text { patient/family } \\
\text { with access } \\
\text { to services for } \\
\text { loss, grief, and } \\
\text { bereavement } \\
\text { support }\end{array}$ & & & & & & \\
\hline $\begin{array}{l}\text { E. Promote } \\
\text { Active } \\
\text { Engagement }\end{array}$ & $\begin{array}{l}\text { E1. Determine } \\
\text { effective and } \\
\text { appropriate ways } \\
\text { to meet client } \\
\text { needs }\end{array}$ & $\begin{array}{l}\text { E2. Identify } \\
\text { level of desired } \\
\text { patient/family } \\
\text { involvement }\end{array}$ & $\begin{array}{l}\text { E3. Build } \\
\text { capacity with } \\
\text { patient/family } \\
\text { towards their } \\
\text { desired level of } \\
\text { independence } \\
\text { and engagement }\end{array}$ & $\begin{array}{l}\text { E4. Promote } \\
\text { engagement in } \\
\text { decision-making } \\
\text { and end-of-life } \\
\text { issues by patient/ } \\
\text { family. }\end{array}$ & $\begin{array}{l}\text { E5. Evaluate } \\
\text { continuously } \\
\text { the level of } \\
\text { patient/family } \\
\text { engagement in } \\
\text { decision-making } \\
\text { and end-of-life } \\
\text { issues. }\end{array}$ & & & \\
\hline
\end{tabular}




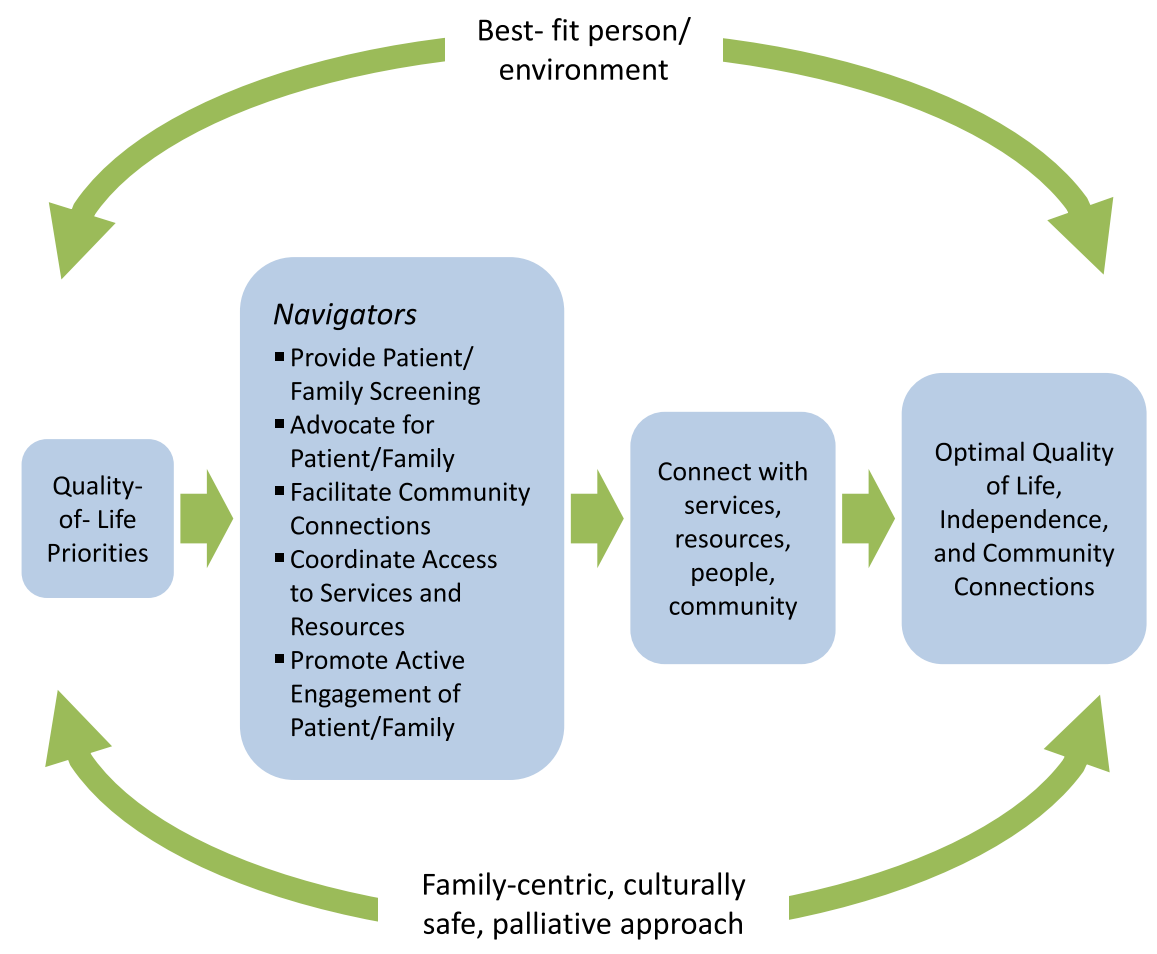

Figure 1: Navigation model representing the five general areas of competencies (GACs) and the conceptual definition of navigation for older rural adults with advanced illness and their families

Another significant difference among NCROA competencies and those of CPAC and NCMN is the goal of improving quality of life of older rural persons and their families with advanced illnesses. For example, in all three areas (NCROA, CPAC, and NCMN) screening and or assessment is mentioned. The focus of the screening/assessment is usually on unmet needs, and on knowledge and assessment of the progression of disease. However, NCROA also includes the assessment of patient and family quality-of-life concerns. Moreover, information provided by the navigator does include information about the disease, but also about possible transitions in quality of life. The navigator also works with the patient/family to prioritize their quality-of-life needs.

Another unique GAC is entitled "facilitating community connections". The specific competencies within this GAC focus not only on finding community resources, but also on how to work with the patient/family to connect and or reconnect with the community. Although there is potential for the competencies to apply to both urban and rural areas, this competency in particular reflects the possible requirement for a different approach in a rural community for older persons and their families. For example, staying connected with the community has been found to be very important to rural older persons and their families (Duggleby et al., 2011; Keating et al., 2013).
Throughout NCROA, there is evidence of a familycentred approach. There is, for example, assessment of patient/family values and beliefs, knowledge of diagnosis and disease progression, and quality-of-life transitions. Navigators need to have the knowledge and skills to screen, advocate, and coordinate access to resources and services and to facilitate community connections for families of older rural persons with advanced illnesses. The health of rural family caregivers of persons with advanced illness has been found to be poor (Duggleby et al., 2014; Robinson et al., 2010), so is naturally of concern to health care providers and policy makers. Moreover, a family-centric approach is also in keeping with the palliative approach as outlined by the Canadian Hospice Palliative Care Association (2013a) report on family caregiving.

The palliative approach is also evident throughout NCROA. For example, under the GAC "coordinate access to services and resources", there are specific competencies in relation to accessing services for loss, grief, and bereavement support, legal wills, and funeral planning, as well as for advanced care planning and goals of care. The focus on quality of life throughout the competencies also reflects the palliative approach.

\section{Limitations}

There are limitations to the approach we used to develop NCROA. The first is that the discussion paper was not 
a systematic review of research studies in the area but an integrative review of research and policy papers. The purpose of the discussion paper was to identify issues, rather than to identify gaps in knowledge, regarding the areas of rural aging, rural palliative care, and navigation. As well, although we reviewed navigation programs in the literature, the focus of the discussion paper was the specific competencies that have been developed and validated in Canada. A final limitation is that the NCROA conceptual definition and resulting competencies are a reflection of the expert panel and require further validation.

\section{Conclusion}

The discussion paper provided the basis for the NCROA navigation framework and definition, which guided the development of navigation competencies for caring for rural older adults and their families with advanced illness. In addition, the Delphi process was successful in bringing together experts in rural aging, rural palliative care, and navigation, along with health care providers and community partners, to inform the development of the competencies. Without this initial ground-breaking work, the competencies would not have reflected the current and critical knowledge of rural aging, rural communities, rural palliative care, and navigation. Future research is needed to validate and evaluate the competencies.

The navigation competencies were specifically designed to help health care providers in assisting rural older palliative patients and their families in ways that honour and respect rural communities and values. Ultimately, these navigation competencies represent a commitment to achieving equity of care for rural older adults and their families with advanced illness. The process we used to develop the conceptual understanding of navigation in this population and the resultant competencies may be of use in the development of navigation competencies for other populations.

\section{References}

Calhoun, E. A., Whitley, E. M., Esparza, A., Ness, E., Greene, A., Garcia, R., et al. (2010). A national patient navigator training program. Health Promotion Practice, 11(2), 205-215.

Canadian Hospice Palliative Care Association. (2012). Synthesis of recommendations from national reports on hospice palliative care: A discussion paper. http: / / www. hpcintegration.ca Accessed 2 April 2015

Canadian Hospice Palliative Care Association. (2013a). Valuing caregiving and caregivers: Family caregivers in the integrated approach to palliative care. Retrieved from http:/ / www.hpcintegration.ca (Accessed 2 April 2105)
Canadian Hospice Palliative Care Association. (2013b). The way forward: An integrative approach to palliative care. Retrieved from http:/ / www.hpcintegration.ca (Accessed 2 April 2105)

Canadian Partnerships Against Cancer (2012). Navigation: A guide to implementing best practices in personcentred care. Toronto, ON: Author. Retrieved from http:/ / www.cancerview.ca/idc/groups/public/documents / webcontent/guide_implement_nav.pdf

Case, M. A. B. (2011). Oncology nurse navigator: Ensuring safe passage. Clinical Journal of Oncology Nursing, 15(1), 33-40. doi: 10.1188/11.CJON.33-40

Castleden, H., Crooks, V. A., Schuurman, N., \& Hanlon, N. (2010). "It's not necessarily the distance on the map....": Using place as an analytic tool to elucidate geographic issues central to rural palliative care. Health and Place, $16,284-290$.

Crooks, V. A., \& Schuurman, N. (2008). Reminder: Palliative care is a rural medicine issue. Canadian Journal of Rural Medicine, 13(3), 139-140.

Duggleby, W., Penz, K., Goodridge, D., Wilson, D., Leipert, B., Berry, P., et al. (2010). The transition experience of rural older persons with advanced cancer and their families: A grounded theory study. BMC Palliative Care, 9(1), 5. doi:10.1186/1472-684x-9-5

Duggleby, W., Penz, K., Leipert, B. D., Wilson, D., Goodridge, D., \& Williams, A. (2011). 'I am part of the community but ...' The changing context of rural living for persons with advanced cancer and their families. Rural and Remote Health, 11, 1733.

Duggleby, W., Williams, A., Holtslander, L., Thomas, R., Cooper, D., Hallstrom, L., et al. (2014). Hope of rural women caregivers of persons with advanced cancer: Guilt, self-efficacy and mental health. Rural and Remote Health, 14, 2561.

Fillion, L., Cook, S., Veillette, A. M., Aubin, M., de Serres, M., Rainville, F., et al. (2012). Professional navigation framework: Elaboration and validation in a Canadian context. Oncology Nursing Forum, 39(1), E58-E69. doi: 10.1188/12. ONF.E58-E69

Goodridge, D., \& Duggleby, W. (2010). Using a quality framework to assess rural palliative care. Journal of Palliative Care, 26(3), 141-150.

Kaasalainen, S., Brazil, K., Williams, A., Wilson, D., Willison, K., Marshall, D., et al. (2012). Barriers and enablers to providing palliative care in rural communities: A nursing perspective. Journal of Rural and Community Development, 7(4), 4-19.

Keating, N. (2008). Rural ageing: A good place to grow old? Bristol, England: The Policy Press, University of Bristol.

Keating, N., Eales, J., \& Phillips, J. E. (2013). Age-friendly rural communities: Conceptualizing 'best-fit'. Canadian Journal on Aging, 32(3), 319-332. 
Keating, N., Swindle, J., \& Fletcher, S. (2011). Aging in rural Canada: A retrospective and review. Canadian Journal on Aging, 30(3), 323-338. doi: 10.1017/S07149808110000250

Kelley, M. L. (2007). Developing rural communities' capacity for palliative care: A conceptual model. Journal of Palliative Care, 23(3), 143.

Linstone, H. A., \& Turoff, M. (2002). The delphi method: techniques and applications. Don Mills, ON: Addison-Wesley. Available from http://is.njit.edu/pubs/delphibook/ delphibook.pdf. Accessed March 9, 2016.

Lockie, S. J., Bottorff, J. L., Robinson, C. A., \& Pesut, B. (2010). Experience of rural family caregivers who assist with commuting for palliative care. Canadian Journal of Nursing Research, 42(1), 74-91.

McKee, M., Kelley, M. L., Guirguis-Younger, M., MacLean, M., \& Nadin, S. (2010). It takes a whole community: The contribution of rural hospice volunteers to the whole-person palliative care. Journal of Palliative Care, 26(2), 103-111.

National Case Management Network. (2012). Canadian core competency profile for case management providers. Retrieved from http:/ / www.ncmn.ca/Resources/Documents/core_ competency_english-2014.pdf

Norton, R. E. (1997). DACUM hanbook (2nd ed.). Columbus, $\mathrm{OH}$ : Ohio State University.

Parliamentary Committee Palliative and Compassionate Care (2011). Not to be forgotten: Care of vulunerable Canadians. Retrieved from http://pcpcc-cpspsc.com/ report

Pedersen, A. E., \& Hack, T. F. (2011). The British Columbia patient navigation model: A critical analysis. Oncology Nursing Forum, 38(2), 200-206. doi: 10.1188/11.ONF. 200-206

Pesut, B., McLeod, B., Hole, R., \& Dalhuisen, M. (2012). Rural nursing and quality end-of-life care: Palliative care ... palliative approach ... or somewhere in-between? Advances in Nursing Sciences, 35(4), 288-304. doi: 10.1097/ ANS.0b013e31826b8687

Robinson, C., Pesut, B., \& Bottorff, J. (2010). Issues in rural palliative care: Views from the countryside. The Journal of Rural Health, 26, 74-84.

Robinson, C., Pesut, B., Bottorff, J., Mowry, A., Broughton, S., \& Fyles, G. (2009). Rural palliative care: A comprehensive review. Journal of Palliative Medicine, 12(3), 253-258.

Robinson, C. A., Pesut, B., \& Bottorff, J. L. (2012). Supporting rural family palliative caregivers. Journal of Family Nursing, 18(4), 467-490.

Wells, K. J., Battaglia, T. A., Dudley, D. J., Greene, A., Calhoun, E. A., Mandelblatt, J. S., et al. (2008). Patient navigation: State of the art or is it science? American Cancer Society, 113(8), 1999-2010. doi: 10.1002/cncr.23815

Wilcox, B., \& Bruce, S. D. (2010). Patient navigation: A "Win-Win" for all involved. Oncology Nursing Forum, 37(1), 21-25. doi: doi: 10:10.1188/10ONF.21-25

Wilson, D. M., Fillion, L., Thomas, R., Justice, C., Bhardwaj, P., \& Viellette, A. M. (2009a). The "good" rural death: A report of an ethnographic study in Alberta, Canada. Journal of Palliative Care, 25(1), 21.

Wilson, D. M., Fillion, L., Thomas, R., Justice, C., Veillette, A. M., \& Bhardwaj, P. (2009b). Planning and providing for a good death using rural French-Canadian and English-Canadian insights. Reviews in the Neurosciences, 20(3-4), 313-319.

Wilson, D. M., Truman, C. D., Thomas, R., Fainsinger, R., Kovacs-Burns, K., Frogatt, K., et al. (2009c). The rapidly changing location of death in Canada, 1994-2004. Social Science and Medicine, 68(10), 1752-1758.

World Health Organization (2013). Definition of palliative care. Retrieved from http://www.who.int/cancer/ palliative/definition/en/ 